from recent publications on flavouring constituents in foods. Coffee aroma rates high with sixty known constituents; the score for Cheddar cheese is thirty-seven, chicken twenty-six, white bread twenty-two, garlic a mere half dozen, whereas strawberry goes to the other extreme with forty-nine. Many of these are reactive substances such as aldehydes and terpenes. The numbers of these minor constituents, often present in quantities below the limits of conventional chemical detection, yet wholly important to our pleasure in eating, offer the most direct example of the complexity of chemical possibilities with which we are concerned in this symposium.

The papers which follow are therefore not to be taken as defining the range of today's topic (which can be interpreted to mean a major part of that branch of study now known as food science), but rather as examples that have been chosen in the hope that they may be of interest to the nutritionist as well as to the food scientist.

\title{
Catalytic destruction of vitamin A and carotene
}

By J. A. Blain and G. Shearer, Department of Applied Microbiology and Biology,
Royal College of Science and Technology, Glasgow

\section{Introduction}

Early studies on vitamin A stability were complicated by the natural association of the vitamin with the highly unsaturated fats of fish oils, and indeed as far back as 1920 it was possible to associate vitamin A deficiency in animals with the destructive effect of dietary fatty peroxides (Hopkins, I920; Drummond \& Coward, 1920). The lability of the principal provitamin, $\beta$-carotene, has also been linked to unsaturated-fat oxidation in vegetable materials, and the unsaturated-fat oxidizing enzyme, lipoxidase, was first studied as a carotene-destroying enzyme (Haas \& Bohn, 1934). Though in some circumstances the stability of vitamin A and carotene in foods and feeding-stuffs may be dissociated from fat oxidation, it would, on the whole, be artificial to divorce the two topics.

The earlier literature on vitamin A stability has been reviewed by Olsen, Harvey, Hill \& Branion (1959) and by Privett (1962).

Details of the oxidative destruction of the vitamin are as yet unknown. Some of the products of enzymically oxidized $\beta$-carotene have been identified by Friend (I96r) who also discussed possible effects of oxidation on biological potency. The general belief that oxidation takes place through the propagation of free-radical chains would appear to be based on the inhibitory action of antioxidants and detection of peroxides in the autoxidizing vitamin (Budowski \& Bondi, r960).

When vitamin $\mathrm{A}$ is added to, or exists in, biological material, its stability will depend in part on physical contact with catalysts present, which in turn will depend on the nature of the dispersion. In animal feeding-stuffs, which have been the subject of most studies, three main types of dispersion may be distinguished: ( $I$ ) as the intrinsic provitamin, as in lucerne or dried grasses, in the form of carotene within the chloroplasts; (2) as the vitamin A of added fish oils or concentrates; (3) as dry 
preparations in which either fish-oil concentrates or synthetic vitamin A esters (usually acetate or palmitate) are associated with gelatin, polysaccharide, and so on as a dry mixture.

In the first two types the vitamin is likely to be intimately associated with unsaturated fats present, and it is known that these readily oxidizable substances promote vitamin A oxidation. In the third type there is a measure of physical isolation from unsaturated fats and also from catalytic factors. The differences associated with dispersion are very considerable.

Booth (1945) showed that when cress leaves were pulped, as much as a quarter of the $\beta$-carotene was lost in $6 \mathrm{~min}$. McDonald (r933) found that the vitamin A of fish oil added to poultry mash could be totally destroyed within $24 \mathrm{~h}$.

On the other hand, when a number of dry vitamin A products were kept in the dark at room temperatures for 6 months, in all of them over $50 \%$ of the vitamin A remained unaltered (Burns \& Quackenbush, I95 I).

It is, of course, difficult to assess to what extent the stability of dry preparations is due to physical isolation, since a high level of antioxidant may be incorporated in the granules while a low concentration is maintained in the feed as a whole. It is well known that carotenoid protection requires a high level of antioxidant (Stuckey, I962), whereas the level permitted in forage crops may be comparatively small (Lea, 1962).

\section{Catalysts}

The catalytic factors that have been studied in relation to the destruction of vitamin A and carotene may be listed as: (I) photochemical, (2) trace metals, (3) unsaturatedfat oxidases, (4) enzymic factor or factors in green leaves.

Photochemical destruction is of particular concern where green crops are allowed to dry on the ground, and under these conditions would appear to be a major factor along with enzymic oxidation in the heavy carotene loss which occurs (Bernstein \& Thompson, I 947; Walsh \& Hauge, I953; Booth, I955).

Trace metals which have long been known to promote the oxidation of unsaturated fats may also destroy vitamin A by this mechanism, but most work on this question has been carried out only on complex systems such as meals and feeds in which fat was present. Manganese has been shown to accelerate destruction of vitamin A in cod-liver oil (Miller, Joukovsky \& Hokenstad, 1942), and a number of workers have shown that deleterious effects result from prolonged contact with vitamin $A$ and the mineral supplements used in feed mixtures (Marcus, I93 I ; Halverson \& Hart, 1950; Ringnes, 1951; Davies \& Worden, 1954). It has been stated that haemin does not accelerate the autoxidation of carotene unless fat is added to the system (Budowski \& Bondi, 1960).

The term 'unsaturated-fat oxidases' has been used to embrace lipoxidases and haematins. Lipoxidases occur in seeds, notably those of the leguminosae, and show specificity towards substrates which, like linoleate, have methylene-interrupted double bonds. The initial products of lipoxidase oxidation are fatty hydroperoxides. The haematins - and here the term is used in the wider sense to include haemoglobin, 
cytochrome c, catalase and so on-act in a similar fashion although they differ in showing long induction periods if their substrate is peroxide-free (Banks, 1944), and probably in reaction mechanism. Unsaturated-fat oxidases are the subject of a recent review by Tappel (I96I). Various reaction mechanisms have been suggested for lipoxidase oxidation (Bergström \& Holman, r948; Tappel, Boyer \& Lundberg, I952; Tappel, I96I). Though it is doubtful if any of these are wholly adequate, there would seem to be agreement that carotene or vitamin A oxidation may be caused by intermediate free radicals produced by the action of lipoxidase or haematins on unsaturated fats. There is evidence that a further free radical chain is produced within vitamin $\mathrm{A}$ in the coupled reaction (Blain, 1963 ).

Much of the interest in the coupled destruction of carotenes by lipoxidase has been in utilizing the reaction for lipoxidase assay and various systems of this nature have been cited in earlier reviews (Holman \& Bergström, I95I). Other studies have been associated with loss of carotenoid colour in doughs, an occurrence desirable in bread doughs, but undesirable in macaroni doughs (Hawthorn \& Todd, I955; Irvine \& Winkler, 195I).

It is not known at present whether lipoxidases are likely to be of importance in vitamin A destruction in feeding-stuffs and, though it might be expected that the ubiquitous haematins would be involved, there is as yet no direct evidence. This point raises the question of whether the enzymic action which destroys carotene in green leaves may be regarded as distinct from that of the unsaturated-fat oxidases already described. Booth, (1960) points out that not only does carotene invariably occur wherever chlorophyll is located but that a carotene-destroying enzyme is normally found in association. This enzyme system has been regarded as a major cause of carotene loss in lucerne (Walsh \& Hauge, 1953) and has been found to occur in the chloroplasts of sugar-beet leaves (Friend \& Mayer, 1960). In general this system would appear to differ from lipoxidase in that it has a $\mathrm{pH}$ optimum about 4 and is inhibited by cyanide (Walsh \& Hauge, 1953) and in that it is stimulated by addition of oxidized linoleate rather than by linoleate (Friend \& Mayer, 1960). These characteristics would conform to the pattern of carotene-bleaching shown by haematins (Blain \& Styles, 1959).

\section{Protection of vitamin $A$ and carotene}

The most generally effective methods of stabilizing vitamin $A$ and carotene in feeds would seem to be the use of antioxidants. Nordihydroguaiaretic acid (NDGA) has given useful protection in fish oils (Dassow \& Stansby, 1949) and in milk and milk products (Cox, Coulter \& Lundberg, 1957), and 6-ethoxy-I,2-dihydro-2,2,4trimethylquinoline (ethoxyquin) and $N, N^{\prime}$-diphenyl-p-phenylenediamine (DPPD) have been found very effective in animal feeds (Siedler, Enzer, Schweigert \& Riemenschneider, 1956). The transmission of DPPD to the fat of the ingesting animals led to its being banned for commercial feeds (Thompson, r958). Propyl gallate, useful in fish oil, has not been found effective in lucerne which is difficult to protect. As the review of Privett ( 1962 ) makes plain, the use of antioxidants has been on a quite empirical basis. 
Model systems have been studied in which antioxidant action on $\beta$-carotene in solution is examined. In mineral-oil solutions a number of gallates were found to extend the induction period for carotene destruction almost a hundredfold, but when used in lucerne they had a negligible protective effect (Bickoff, Coppinger, Livingston \& Campbell, 1952). In general the utility of antioxidants in single-phase systems of this nature cannot be used to predict their value in polyphasic systems.

Most studies on antioxidants for vitamin $A$ have been regarded as concerned with protection against autoxidation although this in fact may often be regarded as tracemetal catalysis (Uri, 196I). Since fat is usually present in conditions of interest in practice, the association of fat oxidation with antioxidants used to protect the vitamin requires consideration. In recent years it has been a practice to add fats to feeds (Armstrong, 1954). These are usually fairly saturated but lacking in natural antioxidants (Privett, I 962). It has been found that they reduce destruction of lucerne carotene (Bickoff, Livingston, Guggolz \& Thompson, 1952; Denton \& Bielanski, I 958; Mitchell \& Silker, I955). On the other hand, a careful study of the oxidation of $\beta$-carotene and vitamin $A$ in mineral oil showed that these substances were destroyed more rapidly when small amounts of fat were added and that more unsaturated fats were more destructive (Budowski \& Bondi, I960).

Some recent experiments of our own are of relevance to the conflicting observations on the effects of fats. We have previously compared the efficacy of several antioxidants for $\beta$-carotene with methyl linoleate in emulsion systems which were stabilized by preparation in agar gels (Blain \& Shearer, I962). In the experiments to be described we have used a similar gel system to examine the effects of fats on the protection of $\beta$-carotene with antioxidants and to find whether ethoxyquin, which has proved to be very good in feeds, is correspondingly effective in this system.

\section{Experimental evidence}

In the experiments using agar gel which are described here, commercial samples of the antioxidants, butylated hydroxyanisole (BHA), ethoxyquin (Santoquin, Monsanto Chemical Co.) and NDGA, were used at a concentration of $0.67 \times 10^{-5} \mathrm{M}$, fat being $74 \times 10^{-5} \mathrm{M}$ and the $\beta$-carotene $2 \cdot 75 \times 1 \mathrm{IO}^{-5} \mathrm{M}$. This amount of carotene is too great to be dissolved in the fat but, as will be shown, appears to be in effective contact with it for oxidation purposes. In general, procedures and conditions were as we have described (Blain \& Shearer, I 962).

In Fig. $I$ is shown the effect of antioxidants on $\beta$-carotene alone. Since this is the Roche Products Ltd synthetic product it may be assumed that it is free of fats and that the antioxidants act directly. When the saturated liquid fat, pelargonic acid, was added to the system the carotene stability was improved both with and without antioxidants (Fig. 2). When methyl linoleate replaced pelargonic acid, the oxidation of unprotected carotene was accelerated but the protection by antioxidants was enhanced (Fig. 3). These experiments illustrate the dual effect of unsaturated fats in promoting carotene oxidation, while at the same time making antioxidants more effective--presumably by improving their contact or orientation with respect to the carotene. Since in the mineral-oil experiments of Budowski \& Bondi (1960) all 


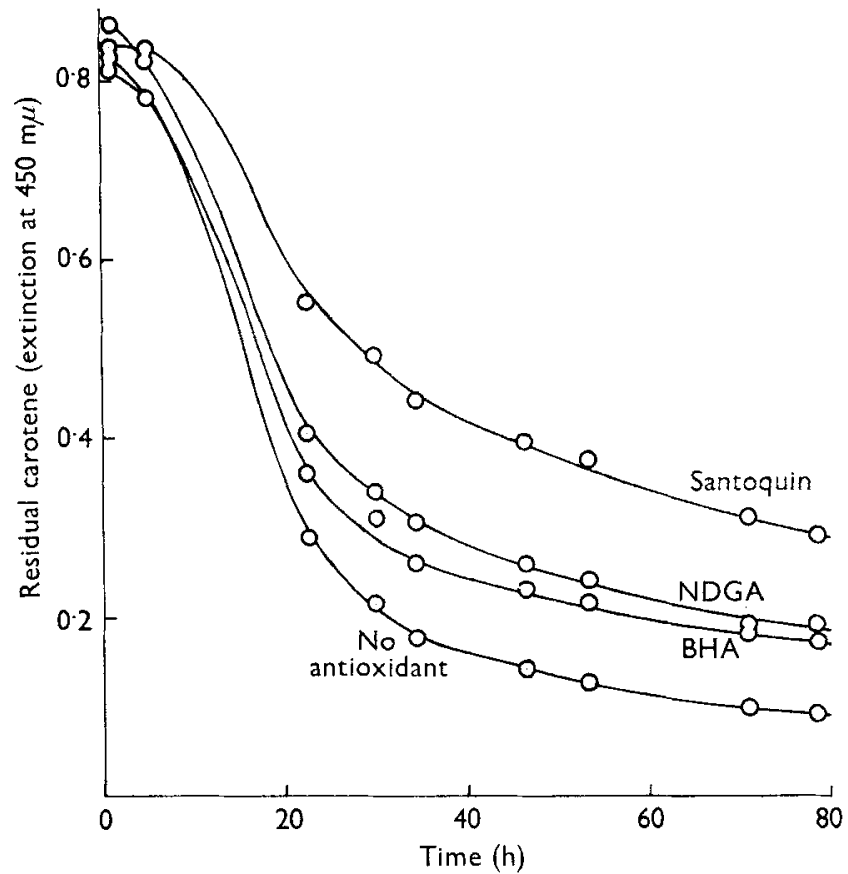

Fig. I. Influence of antioxidants on the rate of autoxidation of $\beta$-carotene in agar gel without added fat.

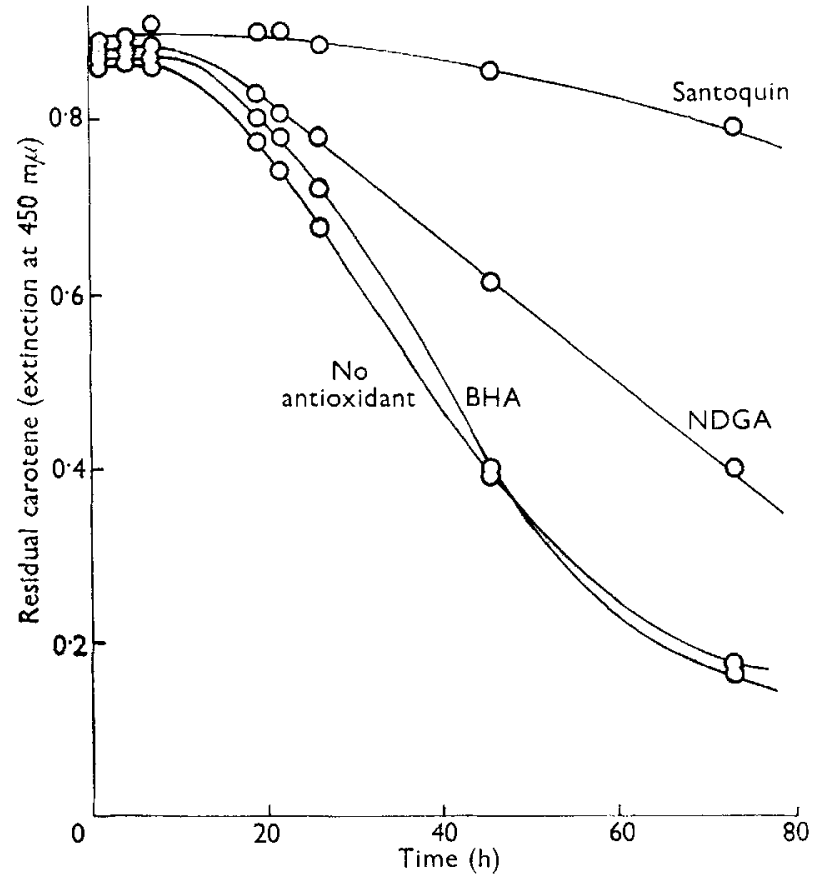

Fig. 2. Influence of antioxidants on the rate of autoxidation of $\beta$-carotene in agar gel with added fat (pelargonic acid). 


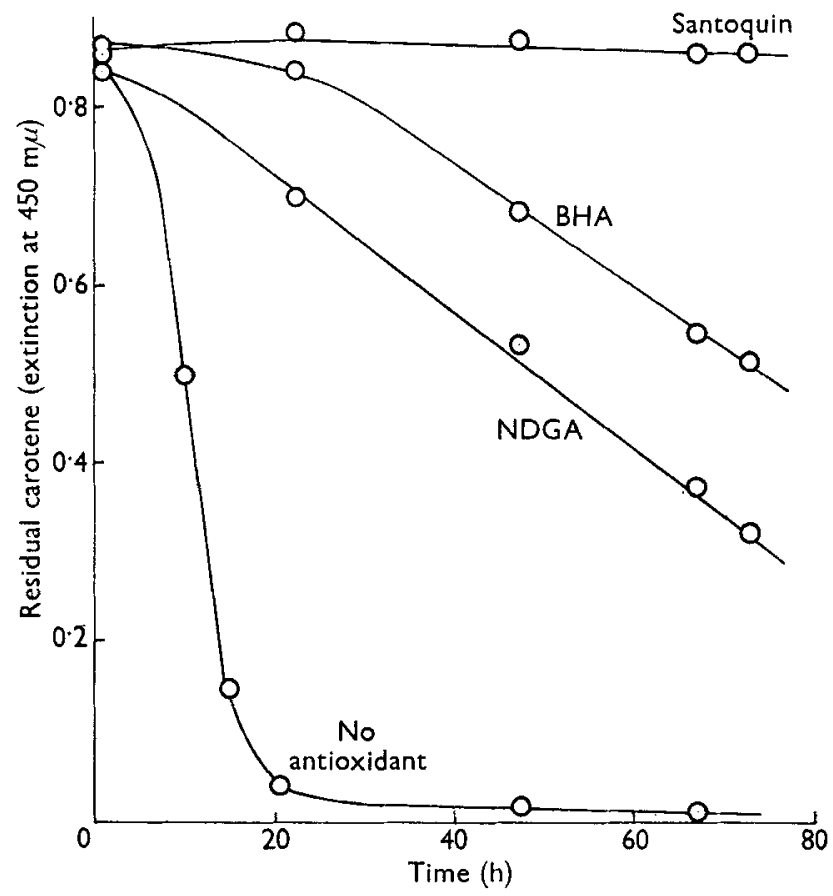

Fig. 3. Influence of antioxidants on the rate of autoxidation of $\beta$-carotene in agar gel with methyl linoleate.

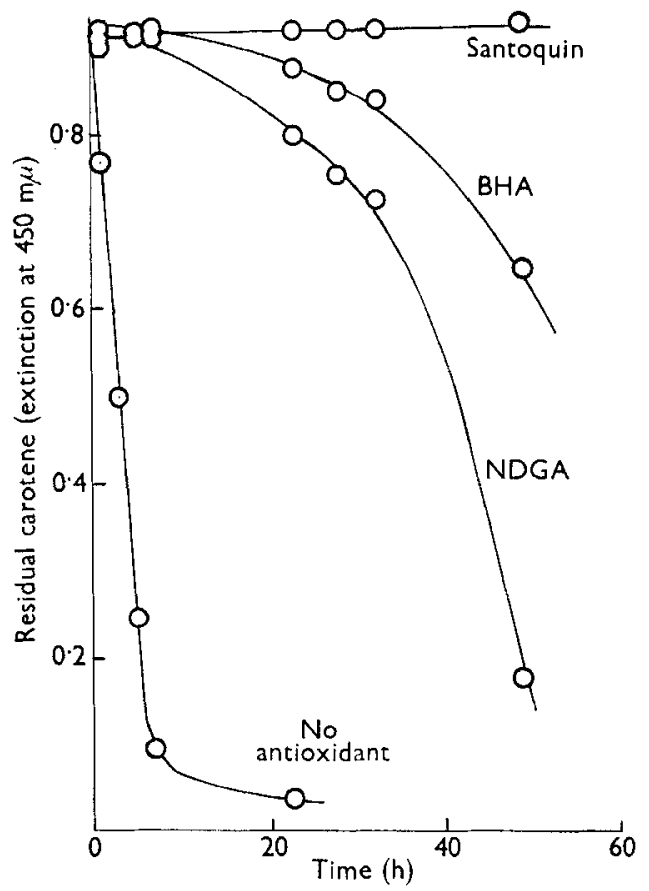

Fig. 4. Influence of antioxidants on the rate of haemoglobin-catalysed oxidation of $\beta$-carotene in agar gel with methyl linoleate.

$22(2) 5$ 


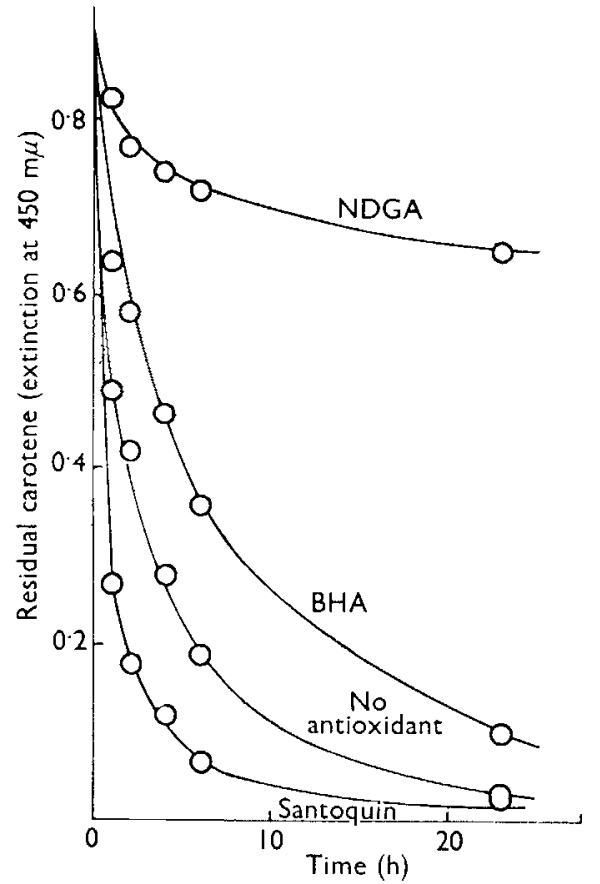

Fig. 5. Influence of antioxidants on the rate of lipoxidase-catalysed oxidation of $\beta$-carotene in agar gel with methyl linoleate.

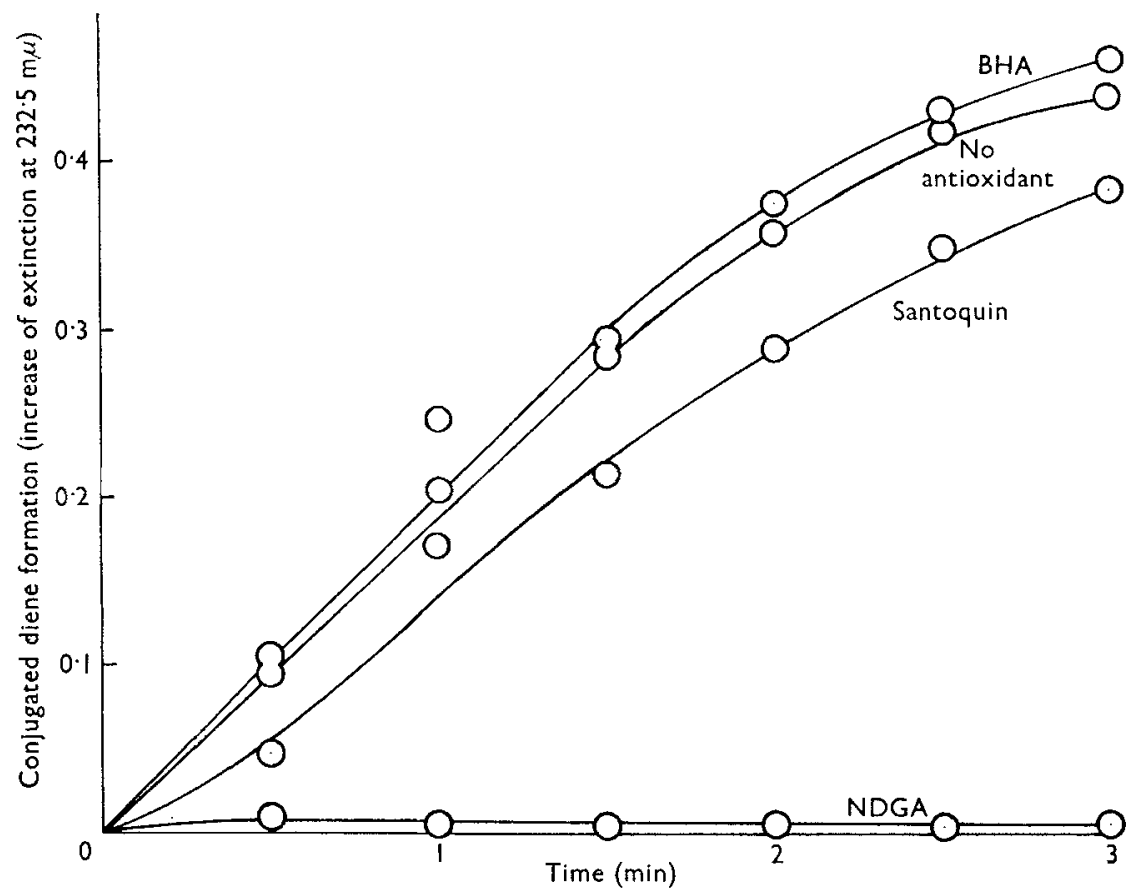

Fig. 6. Influence of antioxidants on the lipoxidase-catalysed oxidation of linoleic acid. 


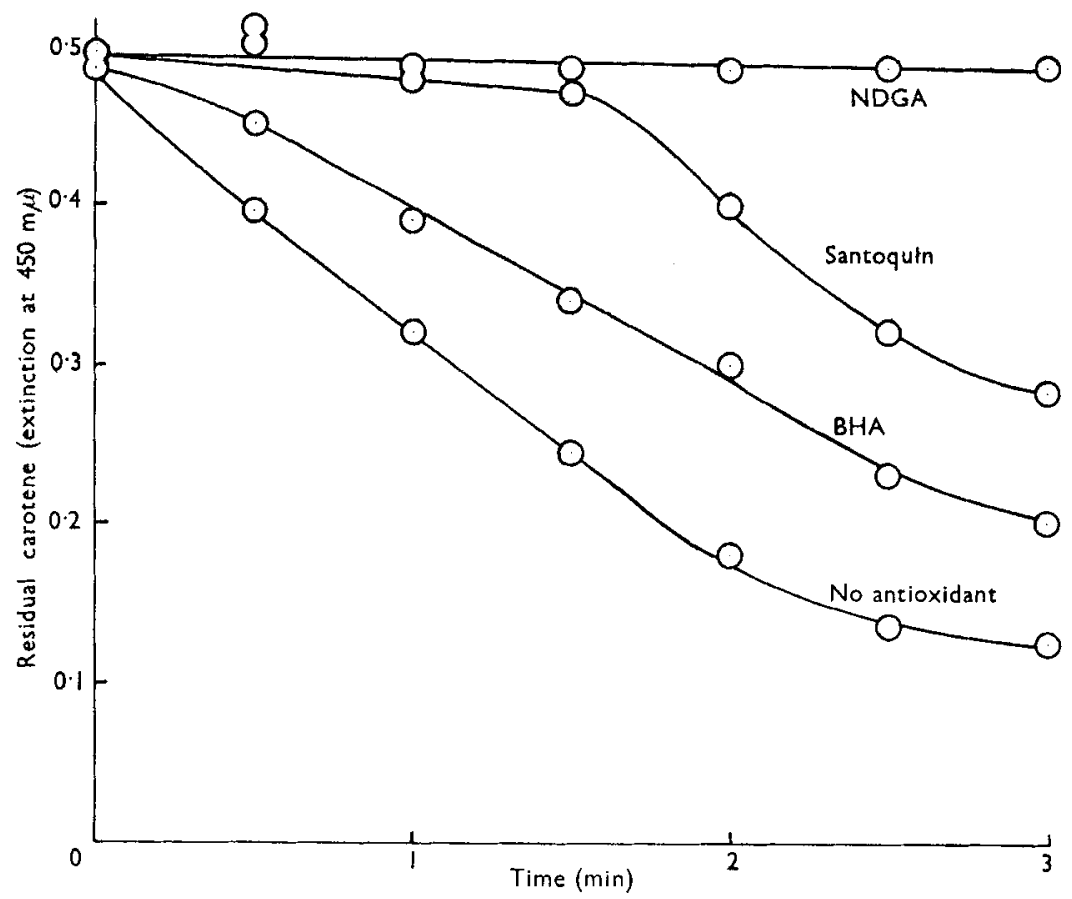

Fig. 7. Influence of antioxidants on the lipoxidase-catalysed oxidation of $\beta$-carotene with linoleic acid.

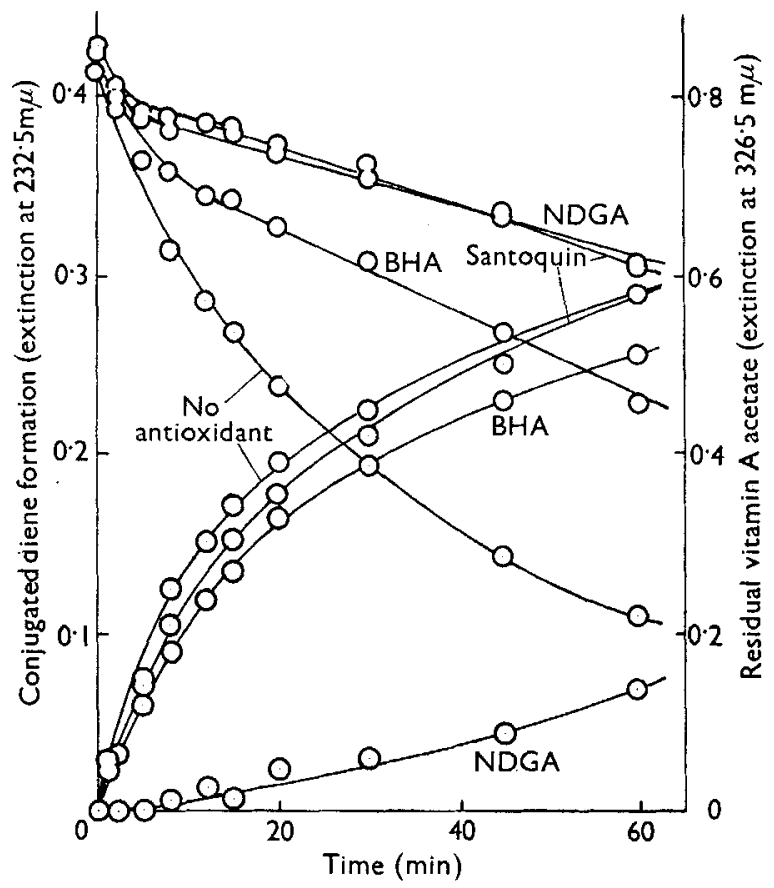

Fig. 8. Influence of antioxidants on the lipoxidase-catalysed oxidation of linoleic acid and the concurrent coupled oxidation of vitamin A acetate. 
compounds were dissolved in the one phase, only the destructive effects of the added fats would be expected. It would also appear that the relative efficacies of antioxidants found with the gel systems conform to those found with natural polyphasic systems such as meals and feeds.

The relative values of antioxidants for carotene in relation to the pro-oxidants involved do not appear to have been specifically studied by other workers. In Figs. 4 and 5 it can be seen that the oxidation of unprotected carotene was greatly accelerated by including in the gels haemoglobin ( $\mathrm{IO}^{-6} \mathrm{M}$ with respect to haem) or crude soya lipoxidase. (The extent of this acceleration was greater than is manifest since the autoxidative experiments used an atmosphere of oxygen, whereas the catalysed ones were carried out in air. We have ascertained that this variation of oxygen tension does not alter orders of efficacy of antioxidants.) The most striking feature of these curves is that for lipoxidase catalysis the NDGA was superior to Santoquin whereas with haemoglobin this position was reversed. Since on this system without fats Santoquin was superior and since several workers have found NDGA to be the best antioxidant against lipoxidase destruction of unsaturated fat, one is led to surmise that in coupled reactions such as that studied here there are two points in the sequence of oxidative events at which antioxidants may be effective and that different antioxidants may be optimal at each point.

Further investigations were carried out with a liquid system of short reaction time using linoleic acid instead of the ester and soya lipoxidase as catalyst. Here the $\mathrm{pH}$ was still 6.5 and concentration of linoleic acid $33 \times 10^{-5} \mathrm{M}, \beta$-carotene $\mathrm{I} \cdot 7 \times$ $10^{-5} \mathrm{M}$ and antioxidants $2 \cdot \mathrm{I} \times \mathrm{IO}^{-5} \mathrm{M}$. It can be seen from Figs. 6 and 7 that the extent of the superiority of NDGA over the other antioxidants in the primary linoleate-oxidizing reaction was not maintained in the secondary carotene-destroying reaction.

The results shown in Fig. 8 were obtained in similar experiments using vitamin A acetate in place of carotene. Antioxidants were $0.62 \times 10^{-5} \mathrm{M}$, vitamin A acetate $2.2 \times 10^{-4} \mathrm{M}$ and linoleate $0.66 \times 10^{-3} \mathrm{M}$. Here again the same pattern of results has been obtained, NDGA being effective in protecting the vitamin A mainly because it inhibits the primary reaction, whereas Santoquin is protecting vitamin A to a much greater extent than can be attributed to its effect on the primary reaction.

We have been concerned to demonstrate these effects over a variety of physical conditions, as the dangers of generalizing from one set of experimental conditions in systems of complexity are obvious. It is of interest that, when antioxidants were used by Siedler et al. (1956) along with added fats in poultry feeds, protection of fats did not correlate with that of vitamin A and carotene, Santoquin being best for the vitamin and relatively poor for the fats.

It would be premature to speculate at present on the factors that determine the loci of operation of different antioxidants on these polyphasic systems. A great deal of the physical chemistry is obscure; the nature of oxidative chain reactions in emulsion systems requires study; knowledge of the behaviour of antioxidants at oil-water surfaces is scanty, and little is known of the mechanism of vitamin A oxidation. 
However, it seems probable that an approach along the lines indicated might lead to antioxidants being used in a fashion less empirical than hitherto.

\section{REFERENCES}

Armstrong, H. A. (1954). American Meat Institute Foundation, Circular no. 9.

Banks, A. (1944). F. Soc. chem. Ind., Lond., 63, 8.

Bergström, S. \& Holman, R. T. (1948). Advanc. Enzymol. 8, 425.

Bernstein, L. \& Thompson, J. F. (1947). Bot. Gaz. I09, z04.

Bickoff, E. M., Coppinger, G. M., Livingston, A. L. \& Campbell, T. W. (1952). F. Amer. Oil Chem. Soc. 29, 51 .

Bickoff, E. M., Livingston, A. L., Guggolz, J. \& Thompson, C. R. (1952). 7. Amer. Oil Chem. Soc. 29, 445 .

Blain, J. A. (1963). In Wissenschaftliche Veröffentlichungen der Deutschen Gesellschaft für Ernährung. Vol. 9, p. 378. [Konrad Lang, editor.] Darmstadt: Steinkopff Verlag.

Blain, J. A. \& Shearer, G. (1962). Chem. EO Ind. p. 217.

Blain, J. A. \& Styles, E. C. C. (r959). Nature, Land., r84, I I4I.

Booth, V. H. (1945). F. Soc. chem. Ind., Lond., 64, I62.

Booth, V. H. (1955). Preservation of Carotene in Dried Green Crops. London: The Association of Green Crop Driers.

Booth, V. H. (1960). F. Sci. Fd Agric. I1, 8.

Budowski, P. \& Bondi, A. (1960). Arch. Biochem. Biophys. 89, 66.

Burns, M. J. \& Quackenbush, F. W. (195I). Industr. Engng Chem. 43, I 592.

Cox, D. H., Coulter, S. T. \& Lundberg, W. O. (1957). F. Dairy Sci. 40, 564.

Dassow, J. A. \& Stansby, M. E. (1949). F. Amer. Oil Chem. Soc. 26, 475.

Davies, A. W. \& Worden, A. N. (1954). F. Sci. Fd Agric. 5, 107.

Denton, A. E. \& Bielanski, E. R. (1958). F. agric. Fd Chem. 6, 853 .

Drummond, J. C. \& Coward, K. H. (I920). Biochem. F. 14, 734.

Friend, J. (1961). Monogr. Soc. chem. Ind. no. I1, p. I60.

Friend, J. \& Mayer, A. M. (1960). Biochim. biophys. Acta, 4I, 422.

Haas, L. W. \& Bohn, R. (1934). US Patents nos. I $957333^{-1} 957337$.

Halverson, A. W. \& Hart, E. B. (1950). F. Nutr. 40, 4 I 5 .

Hawthorn, J. \& Todd, J. P. (I 955). F. Sci. Fd Agric. 6, 501 .

Holman, R. 'T. \& Bergström, S. (I95I). In The Enzymes. Vol. 2, Part 1, p. 559. [J. B. Sumner and K. Myrback, editors.] New York: Academic Press Inc.

Hopkins, F. G. (1920). Brit. med. F. ii, 147.

Irvine, G. N. \& Winkler, C. A. (195I). Cereal Chem. 28, 158 .

Lea, C. H. (1962). In Symposium on Foods : Lipids and their Oxidation, p. 3. [H. W. Schultz, E. A. Day and R. O. Sinnhuber, editors.] Westport, Conn.: Avi Publishing Company.

McDonald, F. G. (1933). F. biol. Chem. 103, 455 .

Marcus, J. K. (I93 I). F. biol. Chem. 90, 507.

Miller, M. W., Joukovsky, V. \& Hokenstad, N. (I942). Poult. Sci. 21, 200.

Mitchell, H. L. \& Silker, R. E. (r955). F. agric. Fd Chem. 3, 69.

Olsen, E. M., Harvey, J. D., Hill, D. C. \& Branion, H. D. (1959). Poult. Sci. 38, 929.

Privett, O. S. (1962). In Autoxidation and Antioxidants. Vol. 2, p. 985. [W. O. Lundberg, editor.] New York: Interscience Publishers.

Ringnes, P. (1951). World's Poult. Congr. Ix. Paris, 2, 77.

Siedler, A. J., Enzer, E., Schweigert, B. S. \& Riemenschneider, R. W. (1956). F. agric. FdChem. 4, 1023.

Stuckey, B. N. (1962). In Symposium on Foods : Lipids and their Oxidation, p. I39. [H. W. Schultz, E. A. Day and R. O. Sinnhuber, editors.] Westport, Conn.: Avi Publishing Company.

Tappel, A. L. (1961). In Autoxidation and Antioxidants. Vol. 1, p. 325. [W. O. Lundberg, editor.] New York: Interscience Publishers.

Tappel, A. L., Boyer, P. D. \& Lundberg, W. O. (1952). F. biol. Chem. r99, 267.

Thompson, C. R. (1958). Feedstuffs, 30, no. 41, p. 52.

Uri, N. (1961). In Autoxidation and Antioxidants. Vol. I, p. 133. [W. O. Lundberg, editor.] New York: Interscience Publishers.

Walsh, K. A. \& Hauge, S. M. (I953). F. agric. Fd Chem. x, I001. 